Article

\title{
Research on the Pressure Ratio Characteristics of a Swash Plate-Rotating Hydraulic Transformer
}

\author{
Chongbo Jing, Junjie Zhou *, Shihua Yuan and Siyuan Zhao \\ School of Mechanical Engineering, Beijing Institute of Technology, Beijing 100081, China; \\ jingchongbo@bit.edu.cn (C.J.); yuanshihua@bit.edu.cn (S.Y.); 1120160729@bit.edu.cn (S.Z.) \\ * Correspondence: bit_zhou50082@163.com or zhoujunjie@bit.edu.cn; Tel.: +86-150-1151-0268
}

Received: 16 May 2018; Accepted: 8 June 2018; Published: 20 June 2018

\begin{abstract}
This paper presents a theoretical model and its experimental validation for the pressure ratio of a swash plate-rotating hydraulic transformer. The structure and principle of the new type of transformer are described. The swash plate-rotating type can reduce the throttling loss caused by the valve plate in traditional hydraulic transformers. The theoretical model of the pressure ratio was derived based on the displacements functioning as the pump and motor in the transformer, accounting for the friction losses. A specific experimental setup including the prototype was established to validate the principle and pressure ratio of the machine. The results show that the transformer has a wider pressure range. The increase in pressure at port A and the rotating speed of the cylinder can reduce the pressure ratio slightly due to the torque loss. The present work indicates the useful potential of the swash plate-rotating hydraulic transformer.
\end{abstract}

Keywords: hydraulic transformer; pressure ratio; swash plate; experimental; energy saving

\section{Introduction}

The hydraulic transformer is a power conversion unit in hydraulic systems, similar to a voltage transformer in electric circuits, which can solve the problem that the hydraulic system is not able to improve the pressure or eliminate the throttling losses. It indicates an approach to significantly improve the energy efficiency of the hydraulic system and to develop a constant pressure network, especially when considering nowadays the requirement of energy conservation and environmental protection [1,2].

Figure 1 depicts the basic principle of a hydraulic transformer. There are three pressure ports: port $\mathrm{A}$ (connecting to the high-pressure source), port $\mathrm{B}$ (connecting to the load), and port $\mathrm{T}$ (connecting to the low-pressure source). Essentially, the hydraulic transformer can be seen as a combination of a hydraulic motor (port A to port T) and a hydraulic pump (port B to port T) [3,4]. It includes two times of power conversion from pressurized fluid to mechanical power and back to fluid. In the traditional system, if the working point shifts from $\mathrm{O}_{1}$ to $\mathrm{O}_{3}$, we need to first increase the flow rate from $Q_{\mathrm{A}}$ to $Q_{\mathrm{B}}$ (working point $\mathrm{O}_{2}$ ) and then reduce the pressure from $p_{\mathrm{A}}$ to $p_{\mathrm{B}}$ by using a valve, which inevitably introduces the throttling loss shown in the figure. However, the transformer enables the direct transformation from $\mathrm{O}_{1}$ to $\mathrm{O}_{3}$ along with the equal power curve without the throttling loss. The extra flow is compensated by port $\mathrm{T}$. Conversely, the hydraulic transformer can also realize a pressure rise from $\mathrm{O}_{3}$ to $\mathrm{O}_{1}$, which is impossible in the traditional system. 


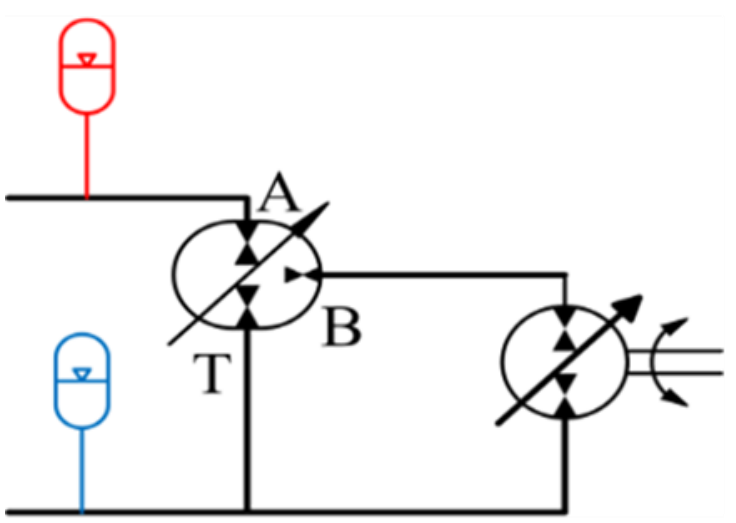

(a)

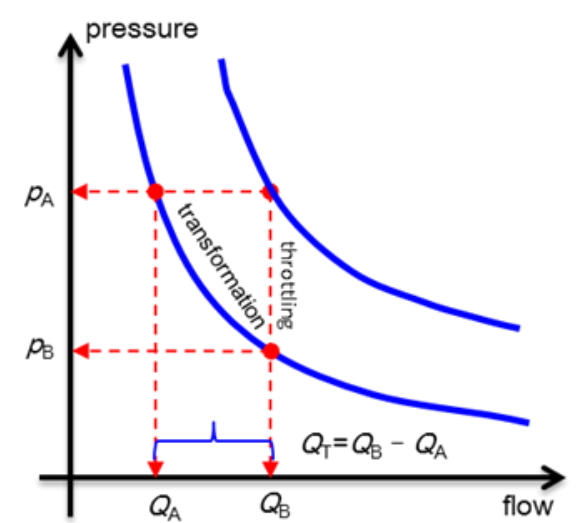

(b)

Figure 1. (a) Layout of hydraulic transformer: port A connecting to high pressure, port B connecting to load and port T connecting to low pressure; (b) Working principle of hydraulic transformer.

Since the 1970s until the present, hydraulic transformers have undergone development from the traditional one-direction and two-direction structures $[5,6]$ to the valve plate-rotating type and various modified structures [7-10]. Currently, valve plate-rotating-type hydraulic transformers occupy the mainstream type, and the related research focuses on the pressure range, efficiency, vibration, noise emission, and control. In reference [7], the influence of the control angle, speed, and frictional resistance of the valve plate on the operation of the Innas hydraulic transformer (IHT) was studied. It was shown that the IHT has a higher efficiency than the traditional hydraulic transformer. To increase the pressure ratio, Dr. Ouyang of Zhejiang University proposed a new structure [10] and conducted experimental verification. In terms of noise, INNAS BV company [11] and Dr. Vael [12] worked on improving the transformer structure. For the control of the hydraulic transformer, researchers from Linkoping University proposed two typical control methods $[13,14]$. One is to use the load flow and cylinder speed as the feedback signal for flow control. The other is to connect the line between the high-pressure source and the load and to use the throttling of the bypass to suppress the torque fluctuations. Recently, researchers have tried to apply the hydraulic transformer to the wave energy converters and drivelines of automobiles $[15,16]$.

However, there is still throttling loss in the valve plate-rotating-type hydraulic transformer. In 2012, Professor Jing from Beijing Institute of Technology invented the rotate-plate hydraulic transformer [17]. The advantage is that the 3 distribution ports ( $\mathrm{A}, \mathrm{B}$ and $\mathrm{T})$ on the valve plate always correspond well with the inlet and outlet ports of the rear cover, which eliminates the throttling loss caused if the valve plate rotates, and allows a wider range of pressure ratios [18].

A new type of hydraulic transformer with a rotating swash plate structure is presented in this work. The theoretical model and its experimental validation for the pressure ratio are described and the relevant results are discussed in the subsequent sections of this paper.

\section{Structure and Principle}

The working principle of the valve plate-rotating hydraulic transformer proposed by Innas BV (Figure 2 shows its structure and the 3 pressure ports) is the same as that of the traditional hydraulic transformer. It integrates the functions of the variable motor and the variable pump, sharing a set of rotating cylinders. It has three ports $(\mathrm{A}, \mathrm{B}, \mathrm{T})$ on the valve plate. It is separately connected from port A to the high-pressure oil source, port $B$ to the load line, and port $T$ to the low-pressure line.

Combining port $\mathrm{A}$ and port $\mathrm{T}$, a hydraulic motor is obtained and the hydraulic pressure will be converted to mechanical energy to drive the shared shaft and cylinder. Moreover, the combination of the $\mathrm{B}$ and $\mathrm{T}$ ports has the function of the hydraulic pump, which converts the mechanical energy transmitted by the cylinder back into hydraulic pressure to the load. During this process, by changing 
the rotation angle of the valve plate or, in other words, the relative position between the flow distribution port and the top dead center (TDC), the functions of the pistons that operate as the pump or the motor will be changed and then a pressure transform between port $\mathrm{A}$ and port $\mathrm{B}$ will be realized.

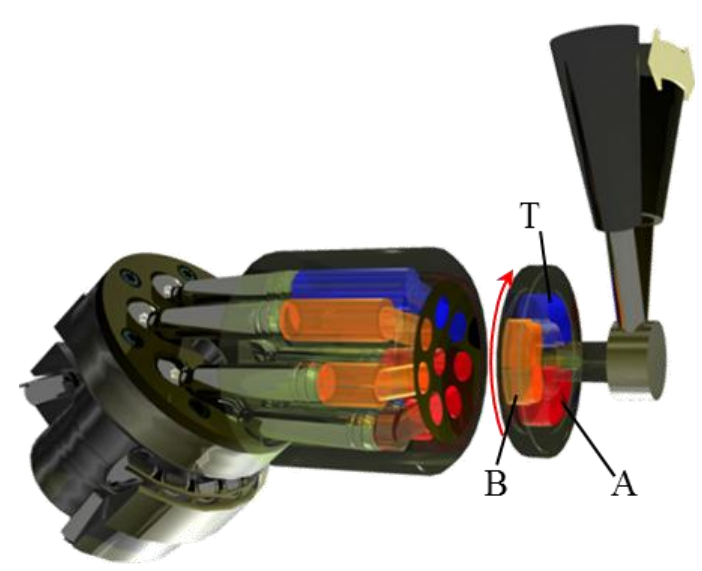

Figure 2. The hydraulic transformer of INNAS Company BV.

However, in order to change the role played by the piston, it is possible to fix the position of the Top Dead Center (TDC) or Bottom Dead Center (BDC) of the transformer and rotate the valve plate to realize the transformation. It is also possible to fix the position of the valve plate to make the TDC (or BDC) rotate in order to change the relative position between the flow distribution ports and TDC in the circumferential direction.

Therefore, if using the swash plate axial piston machine as a base element, the swash plate can be fixed and by rotating the valve plate, the pressure change function can be realized, similar to the prototype of the INNAS BV company Besides, the valve plate can also be fixed at the rear end and the swash plate is supported by the housing and the main shaft through the cover. By rotating the swash plate, the principle of a hydraulic transformer can also be achieved. This is how the swash plate-rotating hydraulic transformer was developed. Figure 3 shows the structure of the new type of hydraulic machine.

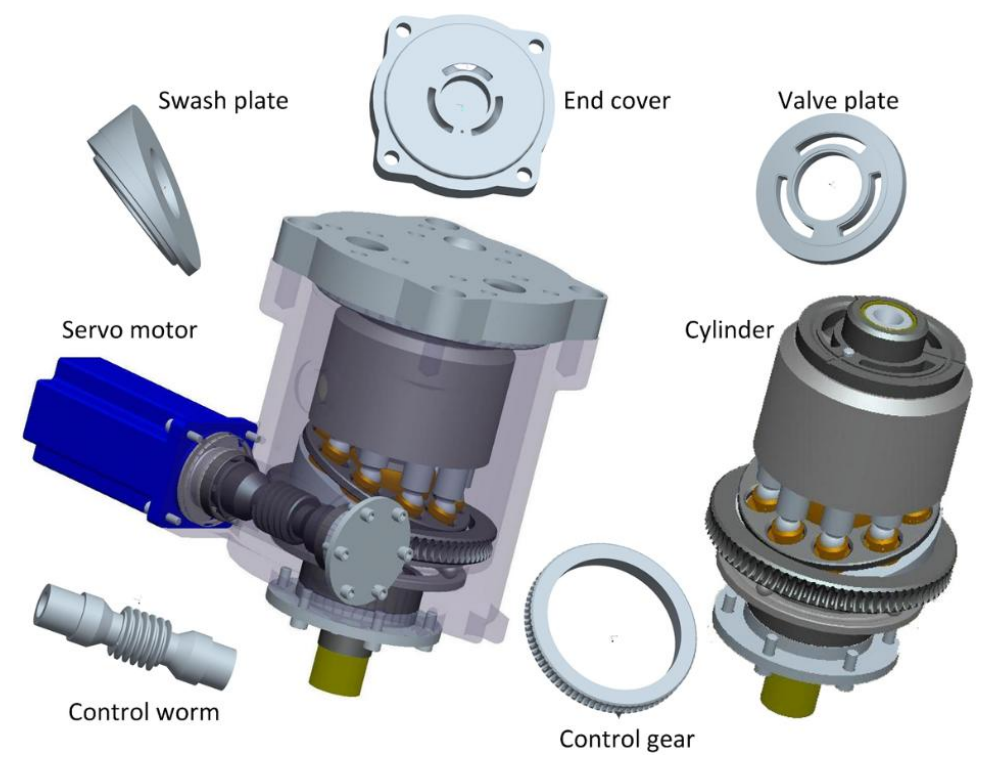

Figure 3. Structure of the swash plate-rotating hydraulic transformer. 
As can be seen from Figure 3, the cylinder, pistons, retain plate, ball joint, and other components of the swash plate-rotating hydraulic transformer are taken from the swash plate axial piston pump. There are also three distribution ports $(\mathrm{A}, \mathrm{B}, \mathrm{T})$ on the valve plate and they correspond to the three oil ports on the rear end cover. The valve plate is fixed in the rear end cover by the pins so its position is settled.

The swash plate of the transformer is redesigned, supported in the housing and the main shaft by the bearings. The rotation of the swash plate is produced by the servo motor through the worm gear mechanism. A speed encoder is connected to one end of the main shaft for testing the rotational speed of the cylinder. By controlling the swash plate angle at different positions, the roles that the pump or motor play by the piston will change and the function of pressure transformation will be generated.

\section{Model of Pressure Ratio}

Referring to the definition of displacement of the pump and motor, the displacement of the hydraulic transformer includes two values, $V_{\mathrm{A}}$ and $V_{\mathrm{B}}$, indicating the displacement between port $\mathrm{A}$ and port $\mathrm{T}$ and the displacement between port $\mathrm{B}$ and port $\mathrm{T}$, respectively.

In viewing Figure 4, suppose the swash plate is rotated by an angle $\delta$; this can be equivalent to the rotation of the valve plate in the opposite direction by the same angle $\delta$. Considering the starting point and the ending point of the position, as shown by the dotted line, the movement of each point at different ports can be calculated:

$$
\left.\begin{array}{c}
X_{\mathrm{A}}=R\left[\cos \left(\delta-\frac{\alpha_{\mathrm{A}}}{2}\right)-\cos \left(\frac{\alpha_{\mathrm{A}}}{2}+\delta\right)\right] \\
X_{\mathrm{B}}=R\left[\cos \left(\alpha_{\mathrm{B}}+\frac{\alpha_{\mathrm{A}}}{2}-\delta\right)-\cos \left(\frac{\alpha_{\mathrm{A}}}{2}-\delta\right)\right] \\
X_{\mathrm{T}}=R\left[\cos \left(\frac{\alpha_{\mathrm{A}}}{2}+\delta\right)-\cos \left(\alpha_{\mathrm{T}}+\frac{\alpha_{\mathrm{A}}}{2}+\delta\right)\right]
\end{array}\right\}
$$

where $X_{A}, X_{B}$, and $X_{T}$ are the displacements of the piston within the angular range of port $A$, port $\mathrm{B}$, and port $T ; \alpha_{A}, \alpha_{B}$, and $\alpha_{T}$ are the effective wrap angles of the distribution ports $A, B$, and T, respectively, and they satisfy

$$
\alpha_{\mathrm{A}}+\alpha_{\mathrm{B}}+\alpha_{\mathrm{T}}=360^{\circ}
$$

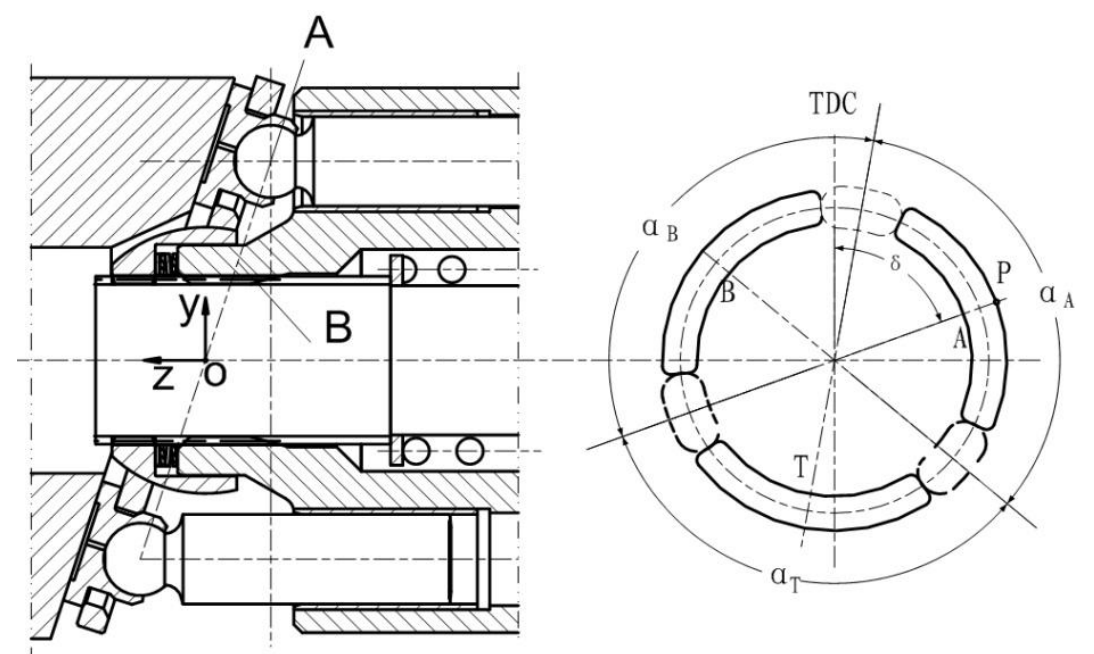

Figure 4. The distribution of the pressure ports on the valve plate.

Then, the displacement of the pump part and motor part in the hydraulic transformer are obtained as follows:

$$
\left.\begin{array}{l}
V_{\mathrm{A}}=\frac{\pi d^{2}}{4} \cdot Z \cdot X_{\mathrm{A}} \cdot \tan \gamma \\
V_{\mathrm{B}}=\frac{\pi d^{2}}{4} \cdot Z \cdot X_{\mathrm{B}} \cdot \tan \gamma
\end{array}\right\}
$$


Combining Equations (1) and (3), the displacements $V_{\mathrm{A}}$ and $V_{\mathrm{B}}$ of the hydraulic transformer can be expressed as follows:

$$
\left.\begin{array}{l}
V_{\mathrm{A}}=\frac{\pi d^{2}}{4} \cdot Z \cdot R \cdot 2 \sin \frac{\alpha_{\mathrm{A}}}{2} \sin \delta \cdot \tan \gamma \\
V_{\mathrm{B}}=-\frac{\pi d^{2}}{4} \cdot Z \cdot R \cdot 2 \sin \frac{\alpha_{\mathrm{B}}}{2} \sin \left(\frac{\alpha_{\mathrm{T}}}{2}+\delta\right) \cdot \tan \gamma
\end{array}\right\}
$$

The pressure ratio of the hydraulic transformer is the ratio of the pressures between port $\mathrm{B}$ and port A.

When the hydraulic transformer works steadily at a certain speed, the torque acting on the rotating cylinder from the three oil ports of the hydraulic transformer should be balanced to the torque loss. The torque balance equation can be written as:

$$
T_{\mathrm{A}}+T_{\mathrm{B}}+T_{\mathrm{f}}=0
$$

where the main torque loss includes the mechanical friction and viscous friction torque (neglect the minor churning loss). The torque from port $\mathrm{A}$ and port $\mathrm{B}$ can be obtained from the displacement using the following equation:

$$
T=\frac{\Delta p V}{2 \pi}
$$

First, if neglecting the torque loss, the ideal pressure ratio can be derived by substituting the displacements into Equation (5):

$$
\Pi=\frac{p_{\mathrm{B}}}{p_{\mathrm{A}}}=\frac{k_{1}}{k_{2}}+\frac{p_{\mathrm{T}}}{p_{\mathrm{A}}} \frac{k_{2}-k_{1}}{k_{2}}
$$

where, $k_{1}=\sin \frac{\alpha_{\mathrm{A}}}{2} \sin \delta$ and $k_{2}=\sin \frac{\alpha_{\mathrm{B}}}{2} \sin \left(\frac{\alpha_{\mathrm{T}}}{2}+\delta\right)$.

It can be seen from Equation (7) that for a given structure the pressure ratio of the hydraulic transformer is related to $p_{\mathrm{T}} / p_{\mathrm{A}}$ and the rotating angle of the swash plate, regardless of the loss. Usually, the pressure at port $\mathrm{T}$ is small so the variation of $p_{\mathrm{T}} / p_{\mathrm{A}}$ is small. It means that the rotating angle of the swash plate becomes the main control parameter of the pressure ratio. Due to the particular structure of the swash plate-rotating hydraulic transformer, the rotating angle of the swash plate can continuously change between $\pm 120^{\circ}$; therefore, the transformer allows continuous operation from positive output to energy recovery conditions.

However, in actual conditions, the above-mentioned torque loss will evidently affect the pressure ratio of the hydraulic transformer. Two simple equations accounting for the mechanical friction and viscous friction torque are given as follows:

$$
\begin{aligned}
\Delta T_{\mathrm{f}} & =C_{\mathrm{f}} \Delta p V \\
\Delta T_{\mathrm{d}} & =C_{\mathrm{d}} \mu \omega V
\end{aligned}
$$

Then, the torque balance equation can be revised as follows:

$$
T_{\mathrm{A}}-\Delta T_{\mathrm{fm}}-\Delta T_{\mathrm{dm}}=T_{\mathrm{B}}+\Delta T_{\mathrm{fp}}+\Delta T_{\mathrm{dp}}
$$

It should be emphasized that the different sign on the two sides of the equation is because the calculation of the theoretical torque in the pump and motor is not the same.

Introducing Equations (8)-(10), it yields:

$$
\left[\left(p_{\mathrm{A}}-p_{\mathrm{T}}\right)-C_{\mathrm{f}}\left(p_{\mathrm{A}}-p_{\mathrm{T}}\right)-C_{\mathrm{d}} \mu \omega\right] k_{1}=\left[\left(p_{\mathrm{B}}-p_{\mathrm{T}}\right)+C_{\mathrm{f}}\left(p_{\mathrm{B}}-p_{\mathrm{T}}\right)+C_{\mathrm{d}} \mu \omega\right] k_{2}
$$


Simplifying the above equation, one can finally obtain the actual pressure ratio of the swash plate-rotating hydraulic transformer as follows:

$$
\Pi=\frac{p_{\mathrm{B}}}{p_{\mathrm{A}}} \frac{k_{1}+\frac{p_{\mathrm{T}}}{p_{\mathrm{A}}}\left(k_{2}-k_{1}\right)+C_{\mathrm{f}}\left[\frac{p_{\mathrm{T}}}{p_{\mathrm{A}}}\left(k_{2}+k_{1}\right)-k_{1}\right]-\frac{C_{\mathrm{d}}}{p_{\mathrm{A}}} \mu \omega\left(k_{2}+k_{1}\right)}{k_{2}+C_{\mathrm{f}} k_{2}}
$$

For the two dimensionless coefficients for calculating the torque loss, they can be recognized by the experimental approach from the bench test data. In this study, Rexroth A4VG125 was taken as the reference pump to design the proposed hydraulic transformer in which $C_{\mathrm{f}}=0.0272$ and $C_{\mathrm{d}}=191,974$.

From the above equation, the real-time pressure ratio of the hydraulic transformer can be determined inversely by the rotating speed of the cylinder. Moreover, according to the established theoretical model of the pressure ratio, it can be seen that the factors influencing the pressure ratio include the rotating angle of the swash plate, the rotating speed of the cylinder, and the pressure at port A.

\section{Experimental Setup}

To validate the theoretical work, a specific test bench for the swash plate-rotating hydraulic transformer was set up in the vehicle transmission lab of Beijing Institute of Technology.

Figure 5 shows the schematic diagram of the experimental system. The three ports $(A, B, T)$ of the prototype machine are respectively connected to the high-pressure line, load line, and the low-pressure line. The high pressure is kept constant by a pre-designed oil source along with an accumulator. The load pressure at port B is generated by a relief valve and the low-pressure line is connected with another oil source through a flow meter. The flow at port $\mathrm{T}$ is significant for making up the flow difference between port A and port B. From the principle of the hydraulic transformer, the flow rates at the three ports can be adjusted by changing the rotating angle of the swash plate. Then, the pressure at port $B$ will change with the flow rate of port $B$ due to the effects of the relief valve, resulting in the variation of the ratio between $p_{\mathrm{A}}$ and $p_{\mathrm{B}}$. In this way, the pressure ratio characteristics of the hydraulic transformer have been investigated.

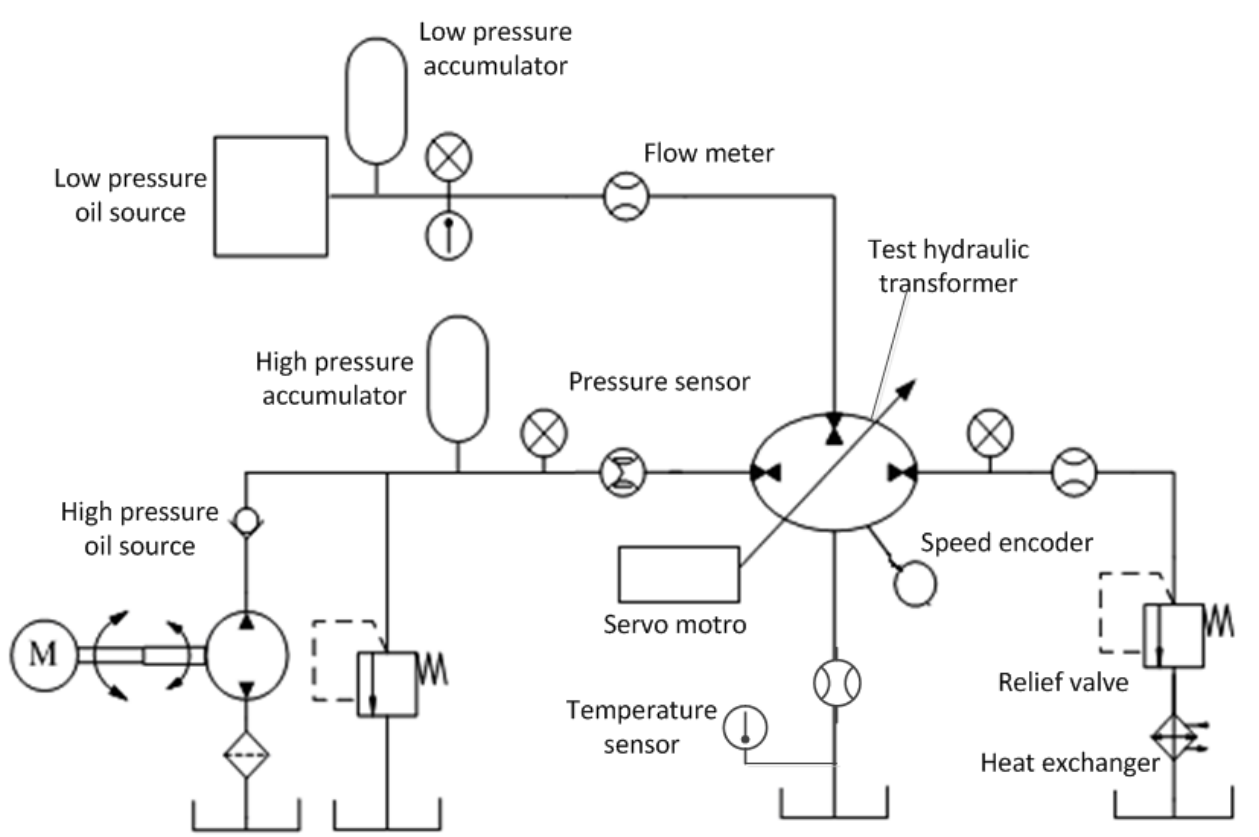

Figure 5. Schematic of the experimental system. 
The low-pressure part of the constant pressure oil source can provide oil from $0.5 \mathrm{MPa}$ to $4 \mathrm{MPa}$ with a maximum flow rate of $100 \mathrm{~L} / \mathrm{min}$. The high-pressure part can provide oil ranging from $2 \mathrm{MPa}$ to $32 \mathrm{MPa}$ and the maximum flow rate can be up to $100 \mathrm{~L} / \mathrm{min}$. The various types of sensors adopted in this test are shown in Table 1.

Table 1. Details of the sensors and equipment used in the test of the inclined-axis hydraulic transformers.

\begin{tabular}{cccc}
\hline Name & Specification & Number & Remarks \\
\hline Rotary encoder & OVW-2 & 1 & Test cylinder speed \\
\hline Temperature sensor & JWB/PT100 & 2 & Measure oil temperature \\
\hline \multirow{2}{*}{ Pressure sensor } & JYB $/ 40 \mathrm{MPa}$ & 2 & Measure $\boldsymbol{p}_{\mathrm{A}}$ and $p_{\mathrm{B}}$ \\
& $\mathrm{JYB} / 1.6 \mathrm{MPa}$ & 2 & Measure $\boldsymbol{p}_{\mathrm{T}}$ \\
\hline \multirow{2}{*}{ Flow meter } & $\mathrm{VS} 4$ & 1 & Measure $\boldsymbol{q}_{\mathrm{A}}$ \\
& EVS3100-1 & 2 & Measure $\boldsymbol{q}_{\mathrm{B}}$ and $\boldsymbol{q}_{\mathrm{T}}$ \\
& EVS3100-3 & 1 & Measure flow rate from case drain port \\
\hline
\end{tabular}

The arrangement of the prototype and the test system is shown in Figure 6.

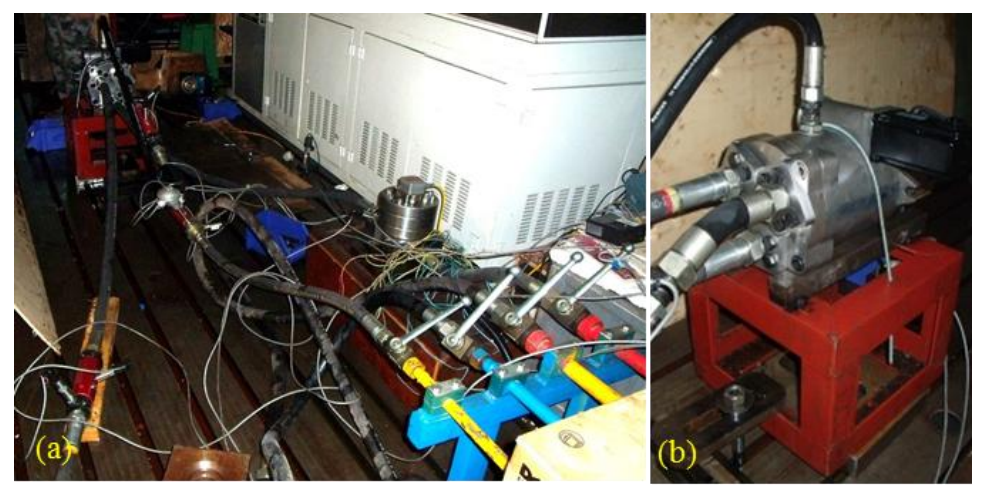

Figure 6. (a) The layout of the test bench; and (b) photo of the test prototype.

The data required for the experiment included 11 parameters: the pressure and flow at each port (port A, port B, and port T) of the hydraulic transformer, and the pressure, flow, and temperature of the oil returning from the transformer casing, the rotational speed of the cylinder and the angle of rotation of the swash plate. Through the analysis of the collected data, the operating features of the machine were investigated.

\section{Results}

This experiment mainly tested the changing trend of the pressure ratio in terms of the influencing factors, such as the rotation angle of the swash plate, the pressure at port A, and the rotation speed of the cylinder. The test results were compared to the theoretical prediction to validate the model and to characterize the operating rules of this particular type of transformer.

It should be emphasized that the results shown in this part were based on a steady state measurement. For the initial verification, we used a manual method to control the cylinder speed. In the test process, a cylinder speed was first set and the load pressure at port B and the rotation angle of the swash plate were adjusted carefully to keep the cylinder speed constant. Then, the pressure ratio was recorded after a steady state was achieved. For each point, we used the mean of three test values. Finally, the curve of the pressure ratio including all the test points could be depicted. 


\subsection{Validation of the Pressure Ratio}

In the first test, the pressures at port $\mathrm{A}$ and port $\mathrm{T}$ were set as $10 \mathrm{MPa}$ and $0.5 \mathrm{MPa}$, respectively. The rotation angle of the swash plate was changed from 0 to $110^{\circ}$. The pressure at port $\mathrm{B}$ of each steady condition was recorded and then the pressure ratio was calculated. The experimental results along with the ideal pressure ratio are shown in Figure 7.

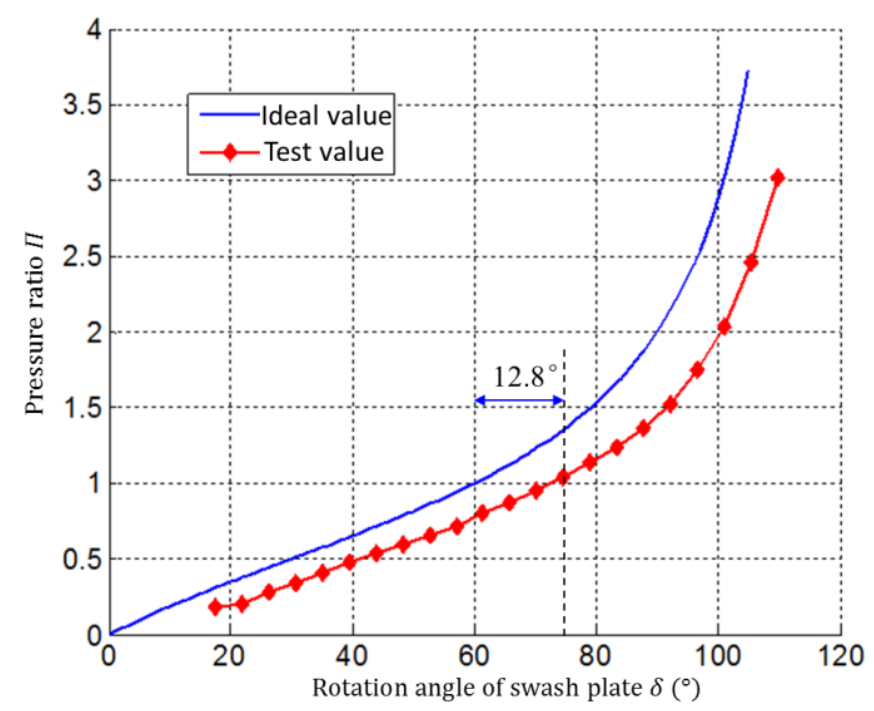

Figure 7. Comparison of pressure ratio.

From Figure 7, the following can be observed:

(1) The pressure ratio of the swash plate-rotating hydraulic transformer changes continuously with the rotation angle of the swash plate. When $\delta=110^{\circ}$, the pressure ratio approaches three, which indicates that the pressure range of the transformer is significantly extended by using this new type (maximum pressure ratio of the valve plate-rotating type is less than $2[3,13]$ ).

(2) The test curve and the theoretical ideal pressure ratio curve (calculated from Equation (7)) follow the same trend. However, the test exerts a delay compared to the theoretical value due to the torque loss being neglected. When the angle of the swash plate is small, the pressure ratio curve is basically consistent with the ideal value curve. When the angle is large, the actual pressure ratio curve deviates from the ideal ratio. The ideal ratio is equal to 1 when $\delta=60^{\circ}$. However, in the test, the pressure ratio was 1 until the angle of the swash plate was increased to $\delta=72.8^{\circ}$.

(3) In the starting process, the cylinder cannot start until the angle of the swash plate is increased to $12^{\circ}$. This indicates that in the starting stage the cylinder needs a larger starting torque to start the rotation and overcome the static friction of each friction pair. However, when the cylinder speed increases, the friction loss decreases rapidly. This also produces a deviation between the test and the ideal state.

\subsection{Effects of Pressure at Port $A$}

Figure 8 shows the pressure ratio changes in terms of the angle of the swash plate under different pressures at port A, without changing other conditions. It can be seen that when the pressure at port A increases, the pressure ratio of the hydraulic transformer will increase slightly at the same angle of the swash plate and cylinder speed. A good match can also be observed in the comparisons between the test and theoretical results. 


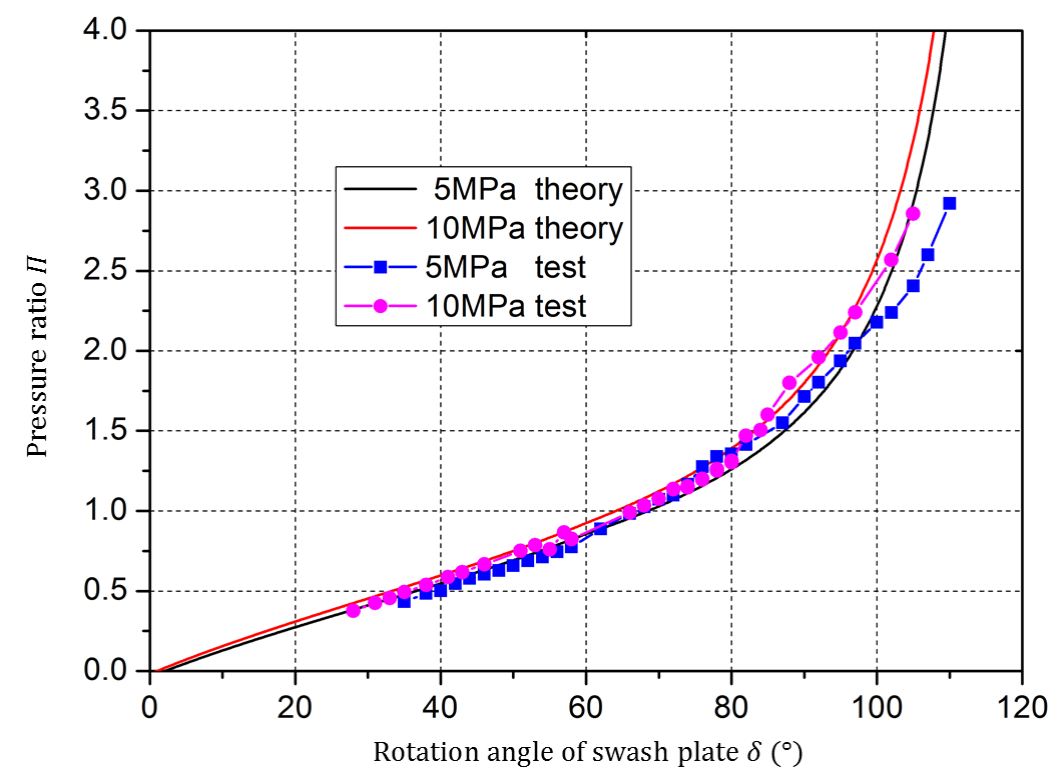

Figure 8. Effects of pressure at port A on the pressure ratio ( $n=800 \mathrm{r} / \mathrm{min})$.

\subsection{Effects of Rotating Speed of the Cylinder}

Keeping the same conditions, the rotation angle of the swash plate was adjusted and the pressure ratios under the cylinder speeds of $600 \mathrm{r} / \mathrm{min}, 800 \mathrm{r} / \mathrm{min}$, and $1000 \mathrm{r} / \mathrm{min}$ were recorded. The curve of the pressure ratio $\Pi$ in terms of different cylinder speeds is shown in Figure 9.

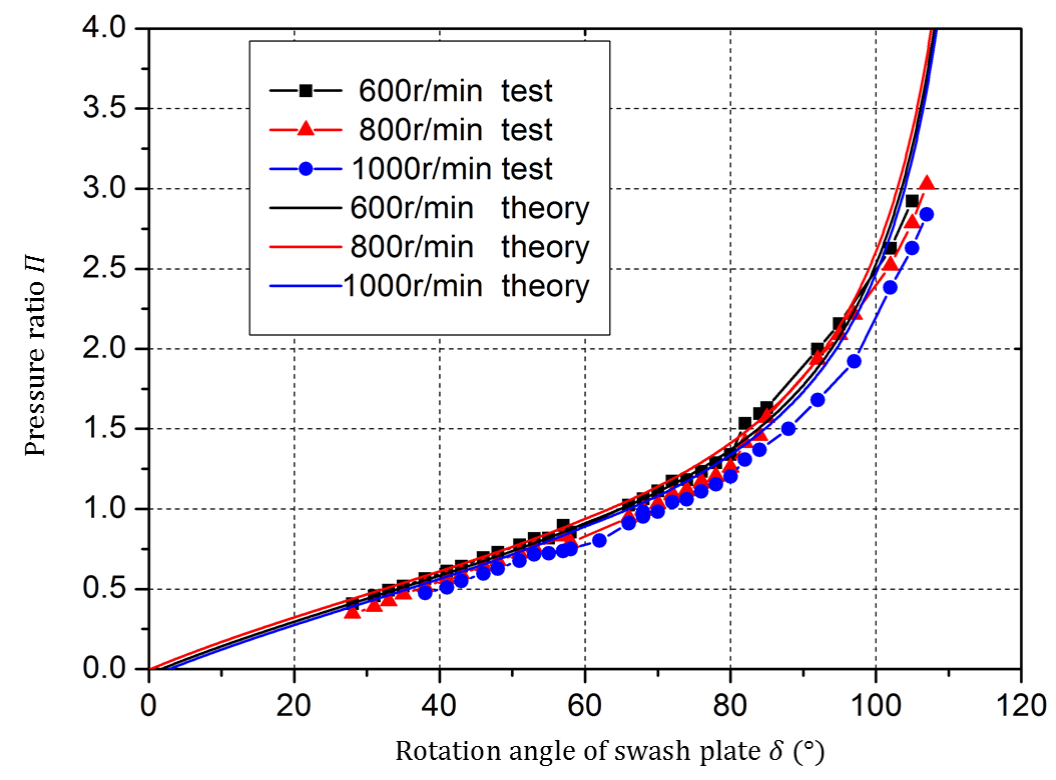

Figure 9. Effects of the rotation speed on the pressure ratio $\left(p_{\mathrm{A}}=10 \mathrm{MPa}\right)$.

As can be seen from Figure 9, the rotation speed of the cylinder has an effect on the pressure ratio of the hydraulic transformer. When keeping the other parameters constant as the rotation speed increases, the pressure ratio curve shifts to the right. This means that it requires a larger rotation angle of the swash plate for high speeds than low speeds to achieve the same pressure ratio. This is mainly due to an increase in the viscous torque loss. At the same rotation angle of the swash plate, the pressure ratio at high speed is smaller than at low speed. The angle of the swash plate must be 
increased to obtain the same pressure ratio. Meanwhile, it can be noticed that the theoretical values are close to the test results for the given cases, indicating the effectiveness of the present model.

\section{Conclusions}

A novel type of hydraulic transformer using a rotating swash plate instead of a rotating valve plate has been developed to reduce the throttling loss and increase the pressure range of this kind of machine. The recent research including the theoretical modeling and experimental validation has been presented in this paper.

By comparing the experimental results for the prototype, the theoretical model has been shown to have a good correlation. As shown with the results, the model is able to properly predict the pressure ratio for different conditions. Furthermore, it was proven that the swash plate-rotating transformer has a wider pressure range. It was also shown that the actual pressure ratio is slightly smaller than the ideal value due to the torque loss. For the same angle of the swash plate, the pressure ratio decreases slightly when the pressure at port A or the rotating speed of the cylinder increases. The current work is also significant for further designs and the application of the swash plate-rotating hydraulic transformer.

Author Contributions: C.J. contributed to the experimental work, including the building of the test system and measurements and data analysis. J.Z. contributed the theoretical work; J.Z. and S.Z. wrote the paper. S.Y. contributed to the revision of this paper.

Acknowledgments: The authors would like to acknowledge financial support from the National Science Foundation of China (Grant No. 51505030) and the Open Foundation of the State Key Laboratory of Fluid Power and Mechatronic Systems (Grant No. 201718).

Conflicts of Interest: The authors declare no conflict of interest.

\section{Nomenclature}

$\begin{array}{ll}C_{\mathrm{d}} & \text { coefficient of mechanical friction torque loss, - } \\ C_{\mathrm{f}} & \text { coefficient of viscous friction torque loss, - } \\ R & \text { distribution radius of the piston, mm } \\ O & \text { working point } \\ T & \text { torque, Nm } \\ V & \text { volume displacement, cc } \\ X & \text { displacement, mm } \\ Z & \text { number of pistons } \\ d & \text { diameter of piston, mm } \\ p & \text { pressure, Pa } \\ k_{1}, k_{2} & \text { defined variable } \\ \Pi & \text { pressure ratio } \\ \alpha & \text { effective wrap angle of distribution ports } \\ \gamma & \text { inclination angle of the swash plate, }{ }^{\circ} \\ \delta & \text { rotation angle of the swash plate, } \\ \omega & \text { angular speed of the cylinder, rad } / \mathrm{s} \\ \mu & \text { viscosity, Pa·s } \\ \text { Subscripts } & \\ \mathrm{A} & \text { pressure port A } \\ \mathrm{B} & \text { pressure port B } \\ \mathrm{T} & \text { pressure port T } \\ \mathrm{p} & \text { pump } \\ \mathrm{m} & \text { motor } \\ & \end{array}$




\section{References}

1. Vacca, A. Energy Efficiency and Controllability of Fluid Power Systems. Energies 2018, 11, 1169. [CrossRef]

2. Vukovic, M.; Leifeld, R.; Murrenhoff, H. Reducing Fuel Consumption in Hydraulic Excavators-A Comprehensive Analysis. Energies 2017, 10, 687. [CrossRef]

3. Jian, J.; Yang, G. Development and research status of hydraulic transformer in hydraulic system. J. Chang'an Univ. 2016, 6, 118-126. (In Chinese)

4. Yang, H.; Ouyang, X.; Xu, B. Development Status of Hydraulic Transformers. J. Mech. Eng. 2003, 39, 1-5. (In Chinese) [CrossRef]

5. Tyler, H.P. Fluid Intensifier: USA. U.S. Patent 3,188,963, 15 June 1965.

6. Herbert, H.K. Hydraulic Transformer: USA. U.S. Patent 3,627,451, 14 December 1971.

7. Achten, P.A.J.; Fu, Z.; Vael, G.E.M. Transforming Future Hydraulics: A New Design of a Hydraulic Transformer. In Proceedings of the 5th Scandinavian International Conference on Fluid Power, Tampere, Finland, 21-23 May 1997.

8. Achten, P.A.J.; Fu, Z. Valving Land Phenomena of the Innas Hydraulic Transformer. Int. J. Fluid Power 2000, 1, 39-47. [CrossRef]

9. Achten, P.A.; van den Brink, T.; van den Oever, J.; Potma, J.; Schellekens, M.; Vael, G.; van Walwijk, M.; Innas, B. Dedicated Design of the Hydraulic Transformer. Proc. IFK 2002, 3, 233-248.

10. Ouyang, X. Study of Hydraulic Transformer; Zhejiang University: Hangzhou, China, 2005. (In Chinese)

11. Vael, G.E.M.; van den Brink, T.L.; Paardenkooper, T.; Achten, P.A.J. Some Design Aspects of the Floating Cup Hydraulic Transformer. In Proceedings of the Eighth Scandinavian International Conference on Fluid Power, Tampere, Finland, 7-9 May 2003.

12. Vael, G.E.M.; Achten, P.A.J.; Potma, J. Cylinder Control with the Floating Cup Hydraulic Transformer. In Proceedings of the 8th Scandinavian International Conference on Fluid Power, Tampere, Finland, 7-9 May 2003.

13. Werndin, R.; Palmberg, J.O. Controller Design for a Hydraulic Transformer. In Proceedings of the 5th International Conference on Fluid Power Transmission and Control, Hangzhou, China, 3-5 April 2001.

14. Werndin, R.; Achten, P.; Sannelius, M.; Palmberg, J.O. Efficiency Performance and Control Aspects of a Hydraulic Transformer. In Proceedings of the 6th Scandinavian International Conference on Fluid Power, Tampere, Finland, 26-28 May 1999.

15. Gaspar, J.F.; Calvário, M.; Kamarlouei, M.; Soares, C.G. Power take-off concept for wave energy converters based on oil-hydraulic transformer units. Renew. Energy 2016, 86, 1232-1246. [CrossRef]

16. Wu, W.; Di, C.; Hu, J. Dynamics of a hydraulic-transformer-controlled hydraulic motor system for automobiles. Proc. Inst. Mech. Eng. Part D J. Automob. Eng. 2016, 230, 229-239. [CrossRef]

17. Jing, C.; Yuan, S.; Hu, J.; Li, X.; Wei, C.; Peng, Z. A Type of Adjustable of Swash Plate-Rotating Hydraulic Transformer: China. China Patent 200,910,244,455.7, 31 December 2012. (In Chinese)

18. Jing, C. Study of Swash Plate-Rotating Hydraulic Transformer; Beijing Institute of Technology: Beijing, China, 2010. (In Chinese)

(C) 2018 by the authors. Licensee MDPI, Basel, Switzerland. This article is an open access article distributed under the terms and conditions of the Creative Commons Attribution (CC BY) license (http://creativecommons.org/licenses/by/4.0/). 